\title{
Development and Scale-Up of a Continuous Manufacturing Process for a Hydrazine Condensation Reaction
}

\author{
Ruiheng Zhu, ${ }^{\dagger}$ Ramesh Reddy, ${ }^{\dagger}$ Man Ding, ${ }^{\dagger}$ Ming Xu, ${ }^{\dagger}$ Chaoyi Deng, ${ }^{\dagger}$ Sam Tadayon, ${ }^{\dagger}$ Hui Li $,{ }^{*},+$ Kristopher \\ Depew, ${ }^{*}$, Benjamin Lane, ${ }^{*}+$ \\ †Shanghai SynTheAll Pharmaceutical Co., Ltd. (“STA”), WaiGaoQiao Free Trade Zone, Shanghai 200131, \\ People's Republic of China \\ ¥Agios Pharmaceuticals, Inc., Cambridge, Massachusetts 02139, United States
}

\section{Table of Contents}

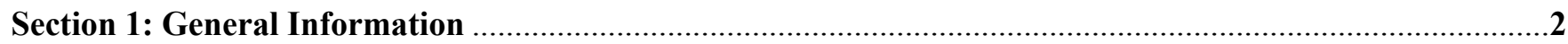

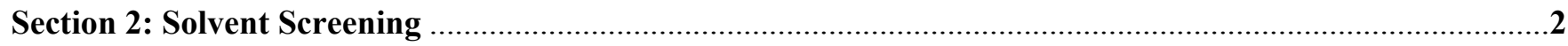

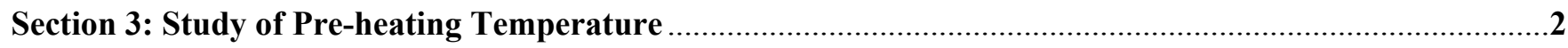

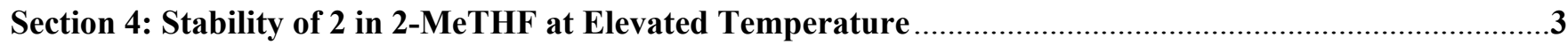

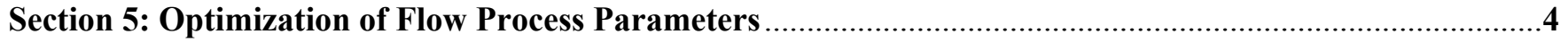

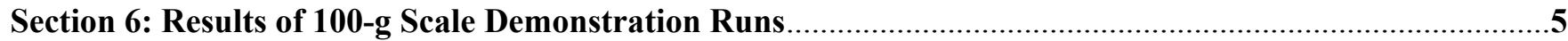

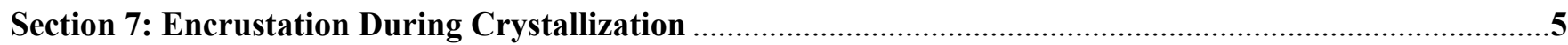

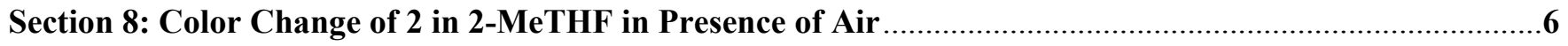

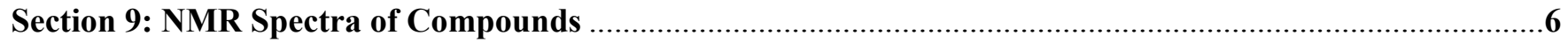




\section{Section 1: General Information}

In-process control of reaction mixtures were performed using offline HPLC analysis. NMR spectra were recorded on a Bruker $400 \mathrm{MHz}$ spectrometer. In-situ infrared spectroscopy data was recorded on a ReactIR 700L from Mettler Toledo. Water content was recorded on a Karl Fischer Titrator from Mettler-Toledo.

Chemicals: 2 was purchased from Nanjing Habo Medicial Technology Co., Ltd ( $>99.8 \%)$ for lab material and Shanghai Anmike Chemical Co., Ltd. for plant material ( $>99.8 \%)$. Hydrazine hydrate ( $85 \mathrm{wt} \%$ ) was purchased from Richjoint for lab material and from Weifang Yanxing Chemical Co., Ltd. for plant material. Both 2 and hydrazine hydrate are also commercially available from Sigma-Aldrich.

Parts for the flow system: PFA tubing (1/8" and 1/4" OD) was purchased from Swagelok and is also commercially available from Cole-Parmer or IDEX Health and Science. PFA tee mixer was purchased from Swagelok. PTFE back pressure regulator (0-500 psi) was purchased from Equilibar.

\section{Section 2: Solvent Screening}

Table S1. Preliminary Solvent Screening for $2^{a}$

\begin{tabular}{|c|c|c|c|}
\hline Solvents & $\begin{array}{l}\text { Solubility } \\
\text { of } 2^{b} \\
(\mathrm{mg} / \mathrm{mL})\end{array}$ & Comments $^{c}$ & Purity ${ }^{d}$ \\
\hline $\mathrm{MeOH}$ & 151 & $\begin{array}{l}\text { Turned cloudy in } 1 \mathrm{~h} \\
\text { Significant amount of precipitates formed after } 3 \text { days }\end{array}$ & $98.0 \%^{e}$ \\
\hline EtOH & 72 & Turned cloudy after $15 \mathrm{~h}$ & $-f$ \\
\hline$i-\mathrm{PrOH}$ & 48 & Turned cloudy in $2 \mathrm{~h}$, low solubility & - \\
\hline$n-\mathrm{BuOH}$ & 29 & Low solubility & - \\
\hline Water & 2 & Low solubility & - \\
\hline MTBE & 51 & No change to appearance after $15 \mathrm{~h}$, low solubility of $\mathbf{2}$ & - \\
\hline THF & $>500$ & Turned dark after 2 days & $98.7^{g}$ \\
\hline 2-MeTHF & 424 & No change to appearance after 5 days & $99.7^{h}$ \\
\hline Acetonitrile & $>500$ & Turned cloudy after stirring for $15 \mathrm{~h}$ & - \\
\hline DMAc & $>500$ & Turned cloudy after stirring for $15 \mathrm{~h}$ & - \\
\hline Ethylene glycol & - & High viscosity & - \\
\hline Anisole & $>400$ & Turned cloudy in $1 \mathrm{~h}$ & - \\
\hline 1,4-Dioxane & $>\mathbf{5 0 0}$ & No change to appearance after 5 days & $99.9^{h}$ \\
\hline NMP & $>500$ & Turned dark after 3-5 days (with and without light) & $98.0-98.5^{i}$ \\
\hline
\end{tabular}

input material: crystalline $2,99.9 \%$ purity by HPLC; ${ }^{b}$ at $25{ }^{\circ} \mathrm{C} ;{ }^{c}$ stirred at $25{ }^{\circ} \mathrm{C}$ for indicated amount of time; ${ }^{d}$ purity of supernatant was analyzed if precipitates were formed; ${ }^{e}$ after 3 days; ${ }^{f}$ not determined; ${ }^{g}$ after 2 days; ${ }^{h}$ after 5 days; ${ }^{i}$ after $3-5$ days

\section{Section 3. Study of Pre-heating Temperature}

A significant amount of precipitate was formed when mixing a 2-MeTHF solution of $\mathbf{2}$ and an EtOH solution of hydrazine hydrate at room temperature. To prevent clogging of the flow system, the 2-MeTHF stream of $\mathbf{2}$ and the EtOH stream of hydrazine hydrate should be pre-heated to a certain temperature so that the reaction mixture can remain as a homogeneous solution after the two streams meet. The pre-heating temperature was studied using the following procedure: 
1) Charge 2 and 2-MeTHF into a round-bottomed flask (RBF) at $25^{\circ} \mathrm{C}$.

2) Slowly add the ethanolic hydrazine hydrate solution into the $\mathrm{RBF}$ at $25^{\circ} \mathrm{C}$. A significant amount of precipitate formed to give a thick slurry at $25^{\circ} \mathrm{C}$.

3) Slowly heat to $70^{\circ} \mathrm{C}$ (internal temperature) with gentle stirring and note the reaction appearance as the temperature climbs. A clear solution was observed starting at $40^{\circ} \mathrm{C}$.

Table S2. Study of Pre-heating Temperatures

\begin{tabular}{c|c|c|l}
\hline $\begin{array}{c}2 \\
\text { Solution }\end{array}$ & $\begin{array}{c}\mathbf{N H}_{2} \mathbf{N H}_{2} \cdot \mathbf{H}_{2} \mathbf{O} \\
\text { Solution }\end{array}$ & $\begin{array}{c}\text { Pre-heating Temperature } \\
\text { (internal temperature) }\end{array}$ & Appearance \\
\hline \multirow{4}{*}{ 2 in 10V } & & $25^{\circ} \mathrm{C}$ & Slurry \\
\cline { 3 - 4 } $2-\mathrm{MeTHF}$ & \multirow{3}{*}{$\begin{array}{c}\mathrm{NH}_{2} \mathrm{NH}_{2} \cdot \mathrm{H}_{2} \mathrm{O} \\
\text { in } 2 \mathrm{~V} \mathrm{EtOH}\end{array}$} & $30^{\circ} \mathrm{C}$ & Slurry \\
\cline { 3 - 4 } & & $40^{\circ} \mathrm{C}$ & Clear and homogeneous solution \\
\cline { 3 - 4 } & & $50^{\circ} \mathrm{C}$ & Clear and homogeneous solution \\
\cline { 3 - 4 } & & $60^{\circ} \mathrm{C}$ & Clear and homogeneous solution \\
\cline { 3 - 4 } & & $70^{\circ} \mathrm{C}$ & Clear and homogeneous solution \\
\hline
\end{tabular}

Conclusion: To avoid precipitate formation when the two streams meet, the pre-heating temperature of the two streams should be $>40^{\circ} \mathrm{C}$.

\section{Section 4: Stability of 2 in 2-MeTHF at Elevated Temperatures}

Because 2 in the 2-MeTHF stream needs to be pre-heated to a temperature $>40{ }^{\circ} \mathrm{C}$ before mixing with hydrazine to avoid the formation of precipitates, the stability of $\mathbf{2}$ at elevated temperatures was tested.

Table S3. Stability of 2 in 2-MeTHF at Elevated Temperatures

\begin{tabular}{|c|c|c|c|c|}
\hline \multicolumn{2}{|c|}{ Input Materials } & \multicolumn{2}{|c|}{ Pre-heating Condition } & \multirow{2}{*}{$\begin{array}{c}\text { Purity of Outflowing } \\
\text { Stream (HPLC, } 250 \mathrm{~nm})\end{array}$} \\
\hline $\begin{array}{c}2 \\
(\mathrm{~g})\end{array}$ & $\begin{array}{c}\text { 2-MeTHF } \\
\text { (V) }\end{array}$ & $\begin{array}{c}\text { Temp } \\
\left({ }^{\circ} \mathrm{C}\right)\end{array}$ & Residence Time (min) & \\
\hline \multirow{7}{*}{2} & \multirow{7}{*}{10} & 25 & 0 & $99.81 \%$ \\
\hline & & \multirow{3}{*}{70} & 5 & $99.85 \%$ \\
\hline & & & 15 & $99.82 \%$ \\
\hline & & & 30 & $99.87 \%$ \\
\hline & & \multirow{3}{*}{140} & 5 & $99.88 \%$ \\
\hline & & & 15 & $99.78 \%$ \\
\hline & & & 30 & $99.69 \%$ \\
\hline
\end{tabular}

\section{Conclusions:}

- At $70{ }^{\circ} \mathrm{C}, \mathbf{2}$ in 2-MeTHF is stable for at least 30 minutes

- At $140{ }^{\circ} \mathrm{C}$, the purity of 2 in 2 -MeTHF decreases slightly $(<0.2 \%)$ over a 30 -minute period

\section{Section 5. Optimization of Flow Process Parameters}

\section{- Preliminary Study of Residence Time}

Various residence times including 5, 10, 20,30 and 40 min were investigated using the flow setup shown in Scheme S1. The 2-MeTHF stream of 2 and the EtOH stream of hydrazine hydrate were flowed through pre-heating loops $\left(1 / 8^{\prime \prime} \mathrm{OD}\right)$, which were submerged in a water bath heated at $70^{\circ} \mathrm{C}$, to reach an outflowing temperature of $40-50{ }^{\circ} \mathrm{C}$. 
The two pre-heated streams entered a pre-heated $\left(140{ }^{\circ} \mathrm{C}\right)$ oven and met at a PTFE tee mixer and then into a PFA plug flow reactor (PFR, 1/8" OD). The outflowing stream was cooled before passing through a back pressure regulator (BPR) for sample collection and off-line HPLC analysis.

Scheme S1. Flow setup

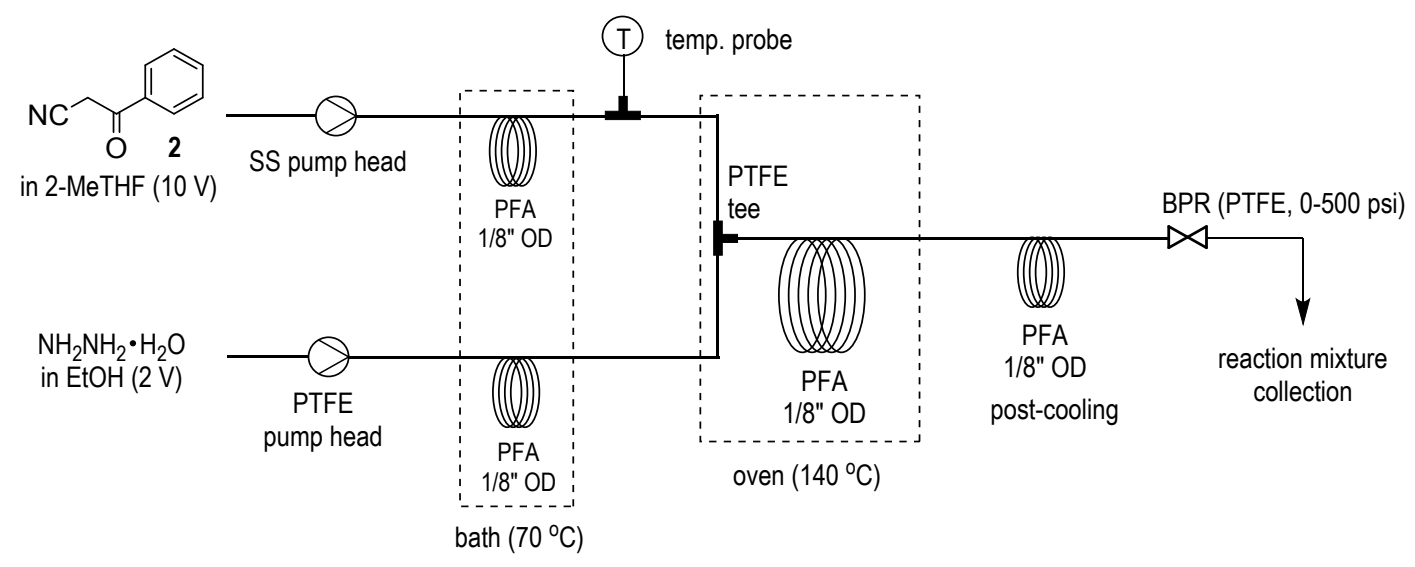

Table S4. Residence Time Study

\begin{tabular}{|c|c|c|c|c|}
\hline \multicolumn{2}{|c|}{ Input Material } & \multicolumn{2}{|c|}{ Reaction condition } & \multirow{2}{*}{$\begin{array}{c}\text { Result } \\
\text { HPLC (Area \%, } 250 \mathrm{~nm}) \\
2 / 1^{a}\end{array}$} \\
\hline 2 (equiv.) & $\begin{array}{c}\mathrm{NH}_{2} \mathrm{NH}_{2} \\
\cdot \mathrm{H}_{2} \mathrm{O} \text { (equiv.) } \\
\end{array}$ & $\begin{array}{c}\text { Oven Temp } \\
\left({ }^{\circ} \mathrm{C}\right)\end{array}$ & $\begin{array}{c}\text { Residence Time } \\
\text { (min) }\end{array}$ & \\
\hline \multirow{5}{*}{$\begin{array}{c}1.0 \\
(30-70 \mathrm{~g} \\
\text { scale })\end{array}$} & \multirow{5}{*}{1.4} & \multirow{5}{*}{140} & 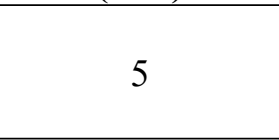 & $\begin{array}{r}9.14 / 89.49 \\
9.05 / 90.32 \\
8.86 / 90.45 \\
\end{array}$ \\
\hline & & & 10 & $\begin{array}{l}4.13 / 95.74 \\
4.08 / 95.80 \\
4.31 / 95.57\end{array}$ \\
\hline & & & 20 & $\begin{array}{l}0.91 / 98.91 \\
1.12 / 98.71 \\
1.10 / 98.74 \\
\end{array}$ \\
\hline & & & 30 & $\begin{array}{l}0.28 / 99.55 \\
0.22 / 99.62 \\
0.10 / 99.71 \\
\end{array}$ \\
\hline & & & 40 & $\begin{array}{l}0.08 / 99.74 \\
0.05 / 99.77 \\
0.10 / 99.71 \\
\end{array}$ \\
\hline
\end{tabular}

$a^{a}$ Three samples were collected for HPLC analysis for each experiment.

Conclusion: Using 1.4 equiv. of hydrazine hydrate, the reaction reached completion $(<0.5 \% 2 / \mathbf{1})$ with a residence time of $\geq 30 \mathrm{~min}$ at $140^{\circ} \mathrm{C}$.

\section{- Study of Reaction Stoichiometry}

Using the flow setup shown in Scheme S1, a few experiments at more than 50-g scale were conducted to search for the optimal balance between equivalents of $\mathrm{NH}_{2} \mathrm{NH}_{2} \cdot \mathrm{H}_{2} \mathrm{O}$ and residence time to achieve the best conversion of 2 to 1. 
Table S5. Further Optimization of Residence Time and Stoichiometry

\begin{tabular}{|c|c|c|c|c|}
\hline \multicolumn{2}{|c|}{ Starting Materials } & \multicolumn{2}{|c|}{ Reaction condition } & \multirow{2}{*}{$\begin{array}{c}\text { Result } \\
\text { HPLC (Area \%, } \\
220 \text { nm) } 2 / 1^{a} \\
\end{array}$} \\
\hline $\begin{array}{c}2 \\
\text { (equiv.) }\end{array}$ & $\begin{array}{c}\mathrm{NH}_{2} \mathrm{NH}_{2} \cdot \mathrm{H}_{2} \mathrm{O} \\
\text { (equiv.) }\end{array}$ & $\begin{array}{c}\text { Oven } \\
\text { Temp }\left({ }^{\circ} \mathrm{C}\right)\end{array}$ & $\begin{array}{c}\text { Residence } \\
\text { Time (min) }\end{array}$ & \\
\hline \multirow{3}{*}{$\begin{array}{c}1.0 \\
(50-70 \mathrm{~g} \\
\text { scale })\end{array}$} & \multirow{3}{*}{1.4} & \multirow{6}{*}{140} & 20 & $\begin{array}{l}1.12 / 98.71 \\
1.10 / 98.74\end{array}$ \\
\hline & & & 30 & $\begin{array}{l}0.28 / 99.55 \\
0.22 / 99.62\end{array}$ \\
\hline & & & 40 & $\begin{array}{l}0.14 / 99.45 \\
0.15 / 99.47 \\
\end{array}$ \\
\hline \multirow{2}{*}{$\begin{array}{c}1.0 \\
(50-100 \mathrm{~g} \\
\text { scale })\end{array}$} & \multirow{2}{*}{1.3} & & 40 & $\begin{array}{l}0.49 / 99.32 \\
0.48 / 99.28\end{array}$ \\
\hline & & & 60 & $\begin{array}{l}0.06 / 99.77 \\
0.07 / 99.66 \\
0.07 / 99.71 \\
\end{array}$ \\
\hline $\begin{array}{c}1.0 \\
(50 \mathrm{~g} \\
\text { scale }) \\
\end{array}$ & 1.2 & & 60 & $0.63 / 99.21$ \\
\hline
\end{tabular}

${ }^{a}$ One to three samples were collected for HPLC analysis for each experiment.

Conclusion: Given the data in Table S5, an achievable reaction conversion specification of $<0.50 \%$ could be set. The conditions to reach the conversion specification would entail mixing 1.4 equiv. of hydrazine hydrate with 1.0 equiv. of 2 at $140{ }^{\circ} \mathrm{C}$ for $\geq 30 \mathrm{~min}$ of residence time. Lower equiv. of hydrazine hydrate would require longer residence times (40-60 minutes) to reach the conversion specification.

\section{Section 6: Results of 100-G Scale Demonstration Runs}

The optimized flow process was confirmed with two 100-g scale runs using the setup and parameters shown in Scheme S2.

Scheme S2. Flow Setup and Process Parameters for 100-g Scale Runs

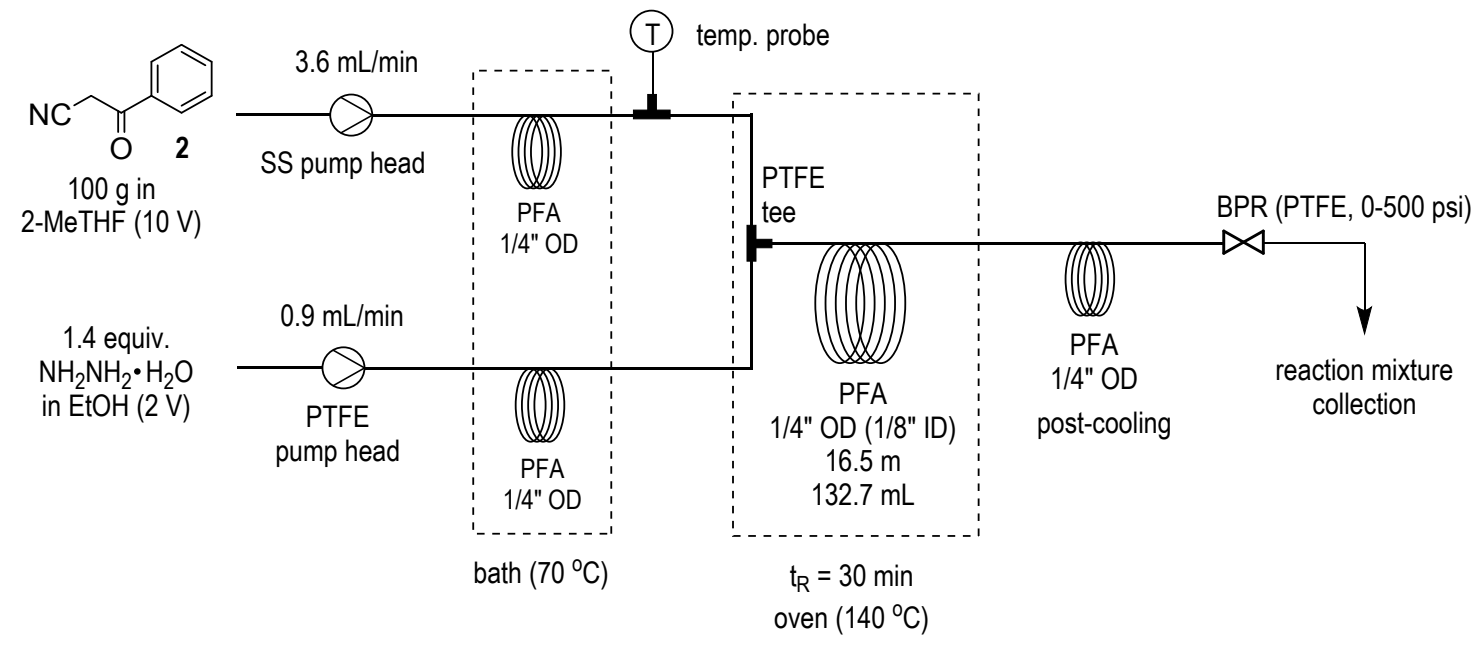


The reaction mixture of each run was collected into three major fractions for IPC analysis. As shown in Table S6, both runs provided $>99 \%$ LC purity of reaction mixture and quantitative solution yields.

Table S6. Results of Two 100-G Scale Runs

\begin{tabular}{|c|c|c|}
\hline Batch \# & IPC by HPLC (2/1,@254 nm) & Comment \\
\hline $1^{\text {st }} 100-\mathrm{g}$ run & $\begin{array}{l}0.22 / 99.6 \\
0.22 / 99.6 \\
0.22 / 99.6\end{array}$ & $\begin{array}{l}1112 \text { g reaction mixture collected } \\
\text { HPLC }(\mathbf{2} / \mathbf{1}, 254 \mathrm{~nm}): 0.16 / 99.6 \\
\text { Assay (wt } \%): 9.7 \% \\
\text { Solution yield: } 98.4 \% \\
\text { Hydrazine content: } 16700 \mathrm{ppm}\end{array}$ \\
\hline $2^{\text {nd }} 100-g$ run & $\begin{array}{l}0.30 / 99.5 \\
0.28 / 99.6 \\
0.29 / 99.6\end{array}$ & $\begin{array}{l}1220 \text { g reaction mixture collected } \\
\text { HPLC }(\mathbf{2} / \mathbf{1}, 254 \mathrm{~nm}): 0.20 / 99.6 \\
\text { Assay (wt } \%): 9.4 \% \\
\text { Solution yield: } 104.6 \% \\
\text { Hydrazine content: } 13100 \mathrm{ppm}\end{array}$ \\
\hline
\end{tabular}

\section{Section 7: Encrustation During Crystallization}

Encrustation was observed during crystallization development. A few experiments were conducted to explore the effect of seed loading and water content on encrustation (Table S7 and Figure S1). At $0.5 \%$ seed loading of 1, more encrustation issues were observed with increased water content of the 2-MeTHF solution (Table S7, entry 1-3). Increasing seed loading from $0.5 \%$ to $2 \%$ gave less encrustation issues (entry 4 versus 1 ). In addition, little encrustation was observed in the $100 \mathrm{-g}$ and $3-\mathrm{kg}$ demo runs, where $2 \%$ seed was used and the water content of $2-$ MeTHF solution was controlled at $0.30-0.55 \%$ (entry 5-6).

Based on the data, higher water content tended to give increased risk of encrustation, while a higher seed loading tended to help overcome the encrustation issues caused by higher water content.

Table S7. Summary of experiments with different seed loading and KF

\begin{tabular}{c|c|c|c|c|c}
\hline Entry & $\begin{array}{c}\text { KF of concentrated 2- } \\
\text { MeTHF solution at } \\
\text { seeding point }\end{array}$ & $\begin{array}{c}\text { Seed } \\
\text { loading } \\
\text { amount }\end{array}$ & $\begin{array}{c}\text { Loss of product solid to } \\
\text { the reactor wall }\end{array}$ & Encrustation ${ }^{a}$ & Scale (g) \\
\hline 1 & $0.83 \%$ & $0.5 \%$ & $>5 \%$ & + & 10.8 \\
\hline 2 & $0.23 \%$ & $0.5 \%$ & $\sim 2 \%$ & - & 11.4 \\
\hline 3 & $0.12 \%$ & $0.5 \%$ & $<1 \%$ & - & 6.2 \\
\hline 4 & $0.75 \%$ & $2 \%$ & $<1 \%$ & - & 100 \\
\hline 5 & $0.40 \%$ & $2 \%$ & $\mathrm{n} / \mathrm{a}{ }^{b}$ & - & 100 \\
\hline 6 & $0.55 \%$ & $2 \%$ & $\mathrm{n} / \mathrm{a}$ & - & 3000 \\
\hline 7 & $0.30 \%$ & $2 \%$ & $\mathrm{n} / \mathrm{a}$ & - & - \\
\hline
\end{tabular}

a "+" encrustation, "-" non-encrustation; ${ }^{b}$ data not available 


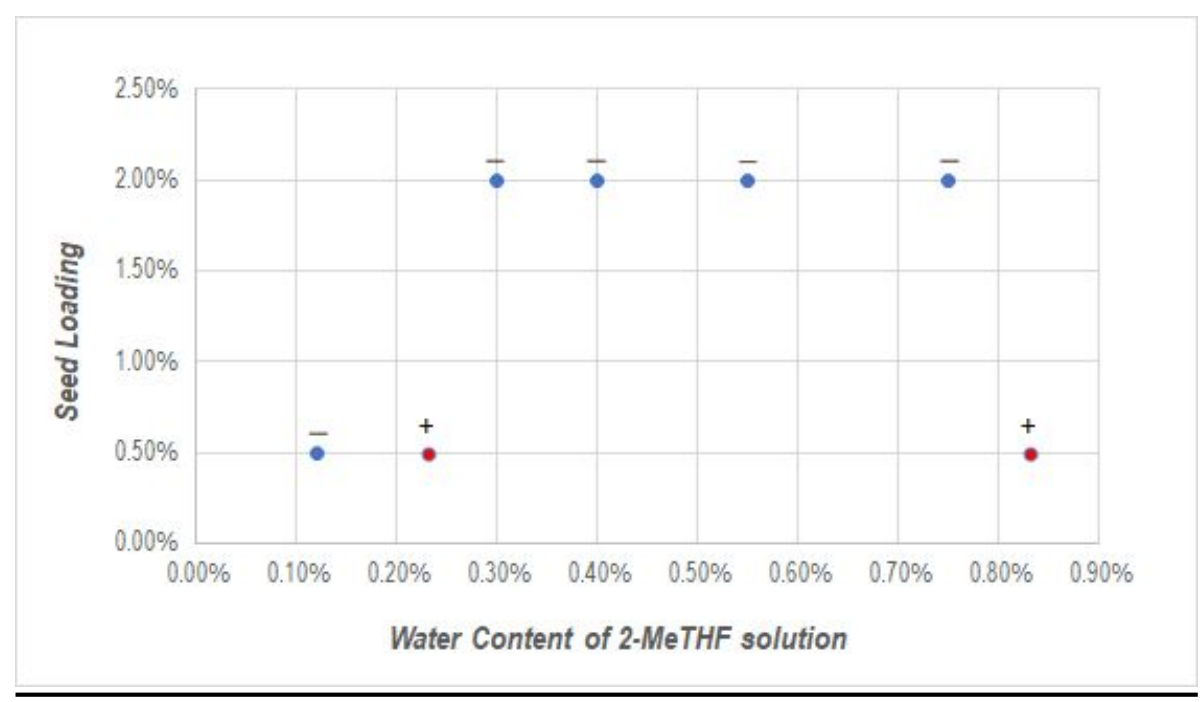

Figure S1. Effect of Seed Loading and Water Content on Encrustation during Crystallization of 1 (blue dots: nonencrustation; red dots: encrustation)

\section{Section 8: Color Change of 2 in 2-MeTHF in Presence of Air}

As shown in Figure S1, the 2-MeTHF solution of $\mathbf{2}$ became colored when exposed to air. TLC analysis of the colored solution also showed the formation of colored spot(s).

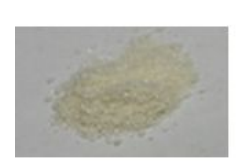

2

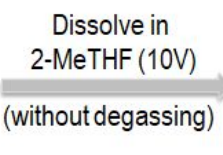

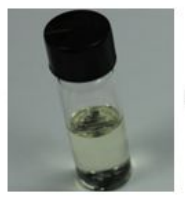
$5 \mathrm{~min}$ at rt
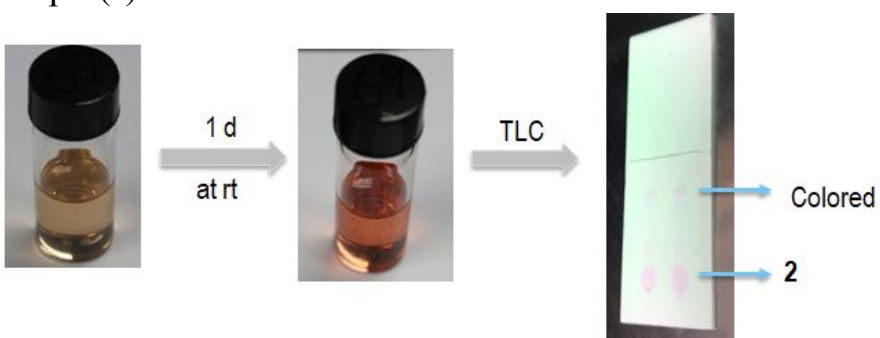

Figure S2. Color Change of 2 in 2-MeTHF

\section{Section 9. NMR Spectra of Compounds}


- ${ }^{1} \mathrm{H}-\mathrm{NMR}$ of $\mathbf{1}$ in $\mathrm{CD}_{3} \mathrm{OD}$
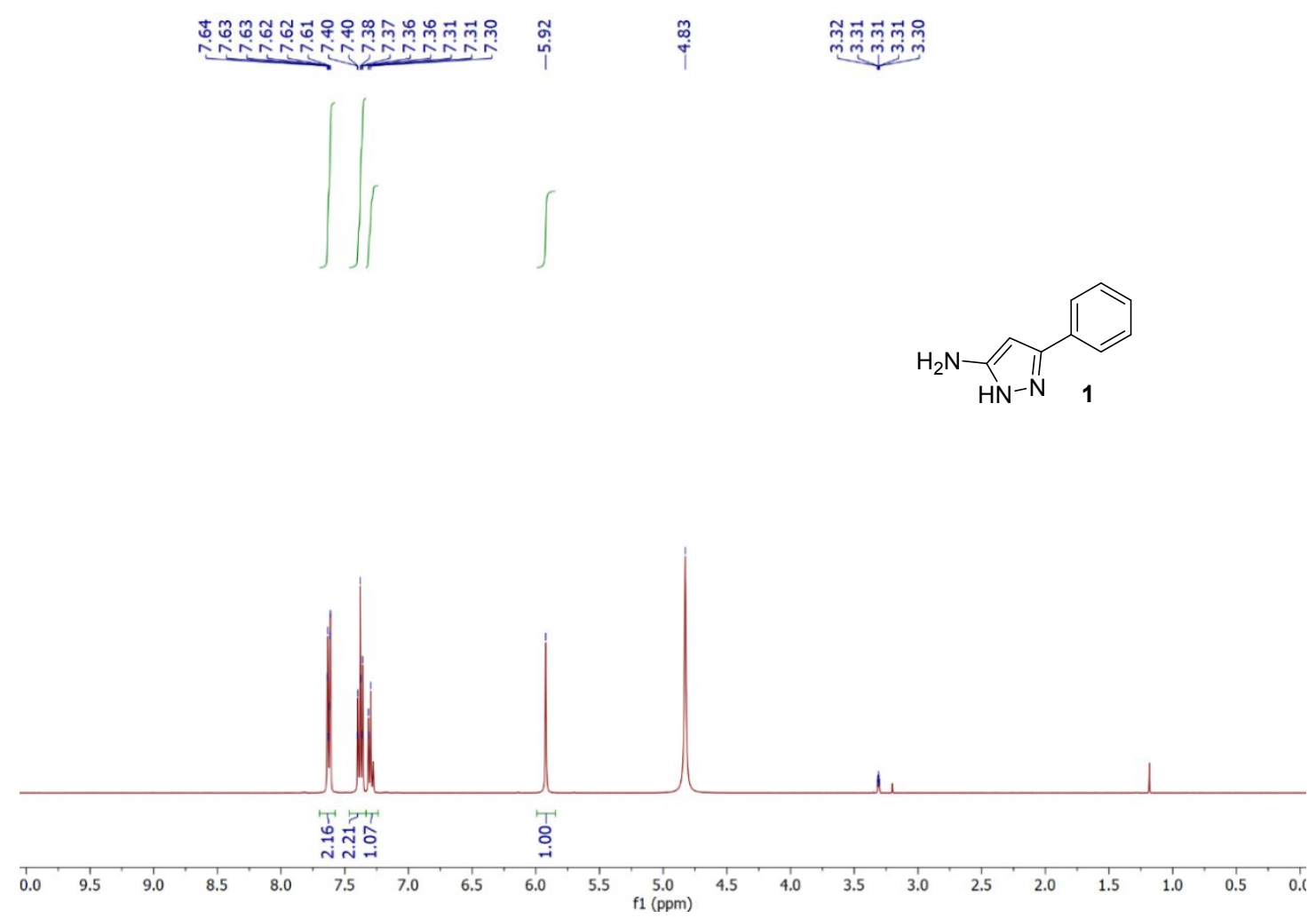

- ${ }^{13} \mathrm{C}-\mathrm{NMR}$ of $\mathbf{1}$ in $\mathrm{CDCl}_{3}$

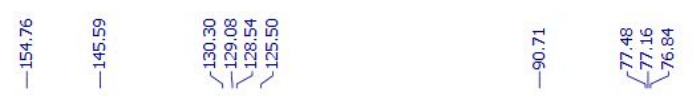
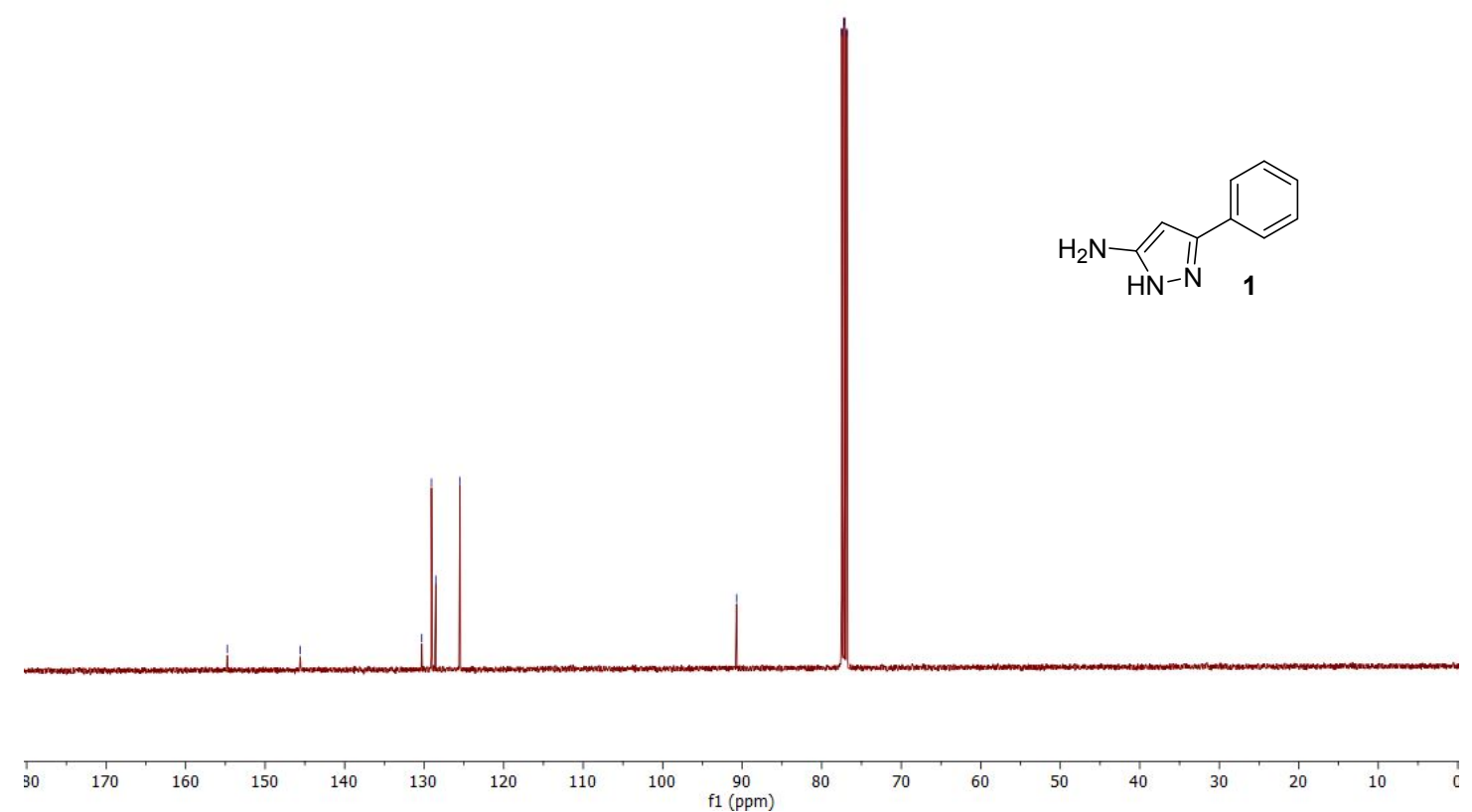

- ${ }^{1} \mathrm{H}-\mathrm{NMR}$ of Precipitates after Holding $2 / \mathrm{MeOH}$ for Days (in DMSO- $d_{6}$ ) 

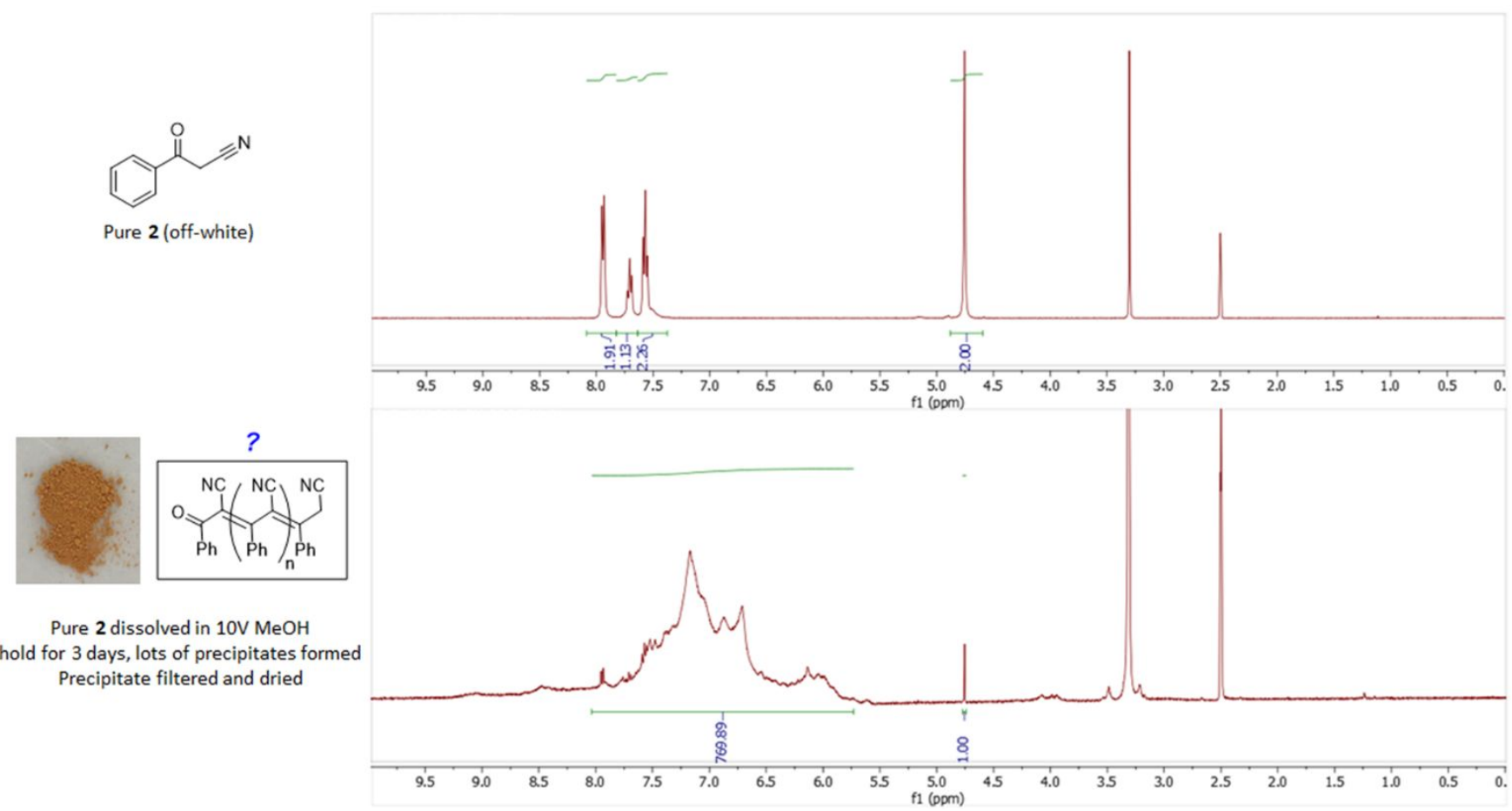

- ${ }^{1} \mathrm{H}-\mathrm{NMR}$ of 3 Precipitated after Mixing 2/2-MeTHF and $\mathrm{NH}_{2} \mathrm{NH}_{2} \cdot \mathrm{H}_{2} \mathrm{O} / \mathrm{EtOH}$ at $25^{\circ} \mathrm{C}$ (in DMSO- $d_{6}$ )

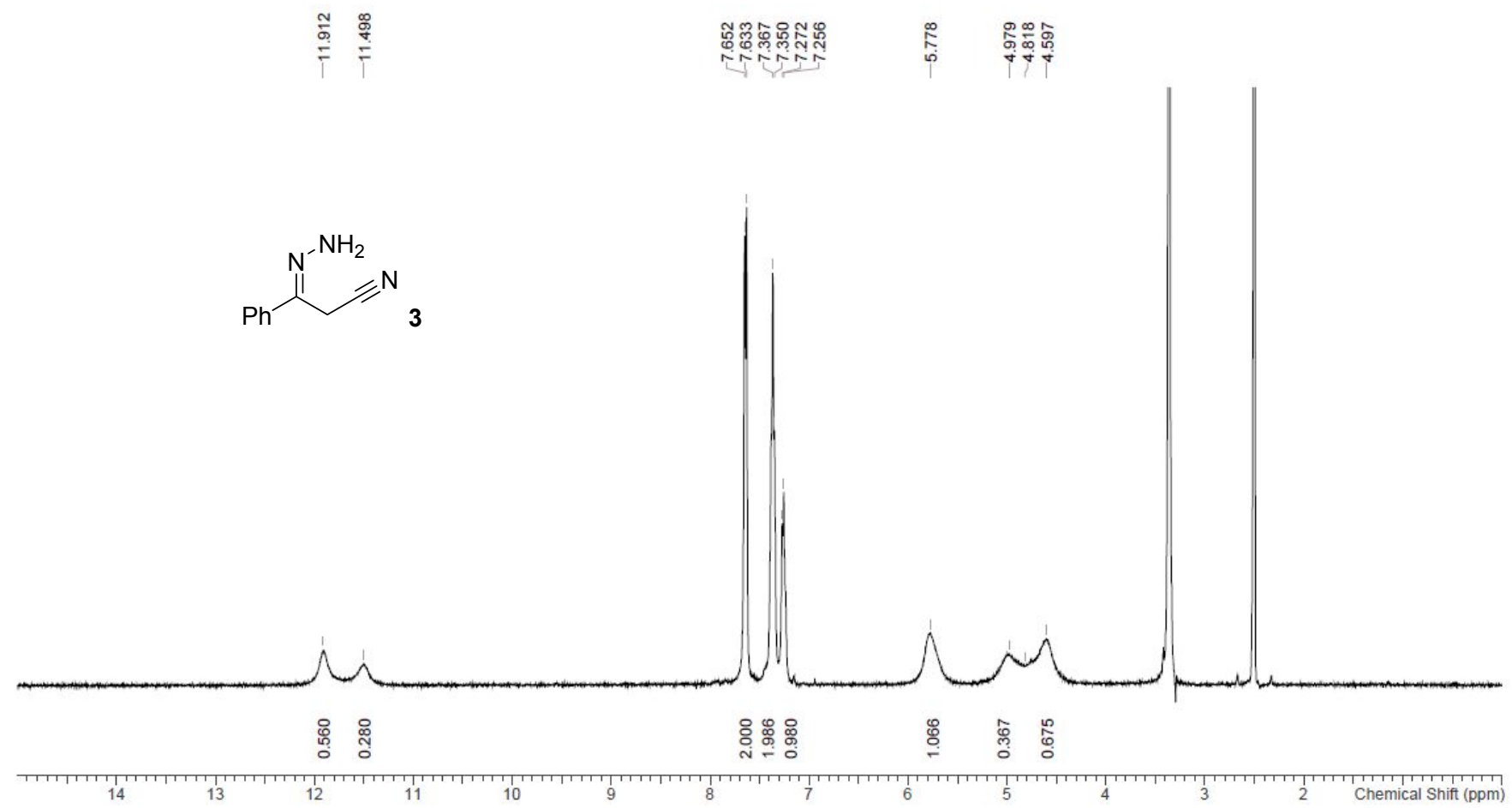

- ${ }^{13} \mathrm{C}-\mathrm{NMR}$ of 3 Precipitated after Mixing 2/2-MeTHF and $\mathrm{NH}_{2} \mathrm{NH}_{2} \cdot \mathrm{H}_{2} \mathrm{O} / \mathrm{EtOH}$ at $25{ }^{\circ} \mathrm{C}$ (in DMSO- $d_{6}$ ) 


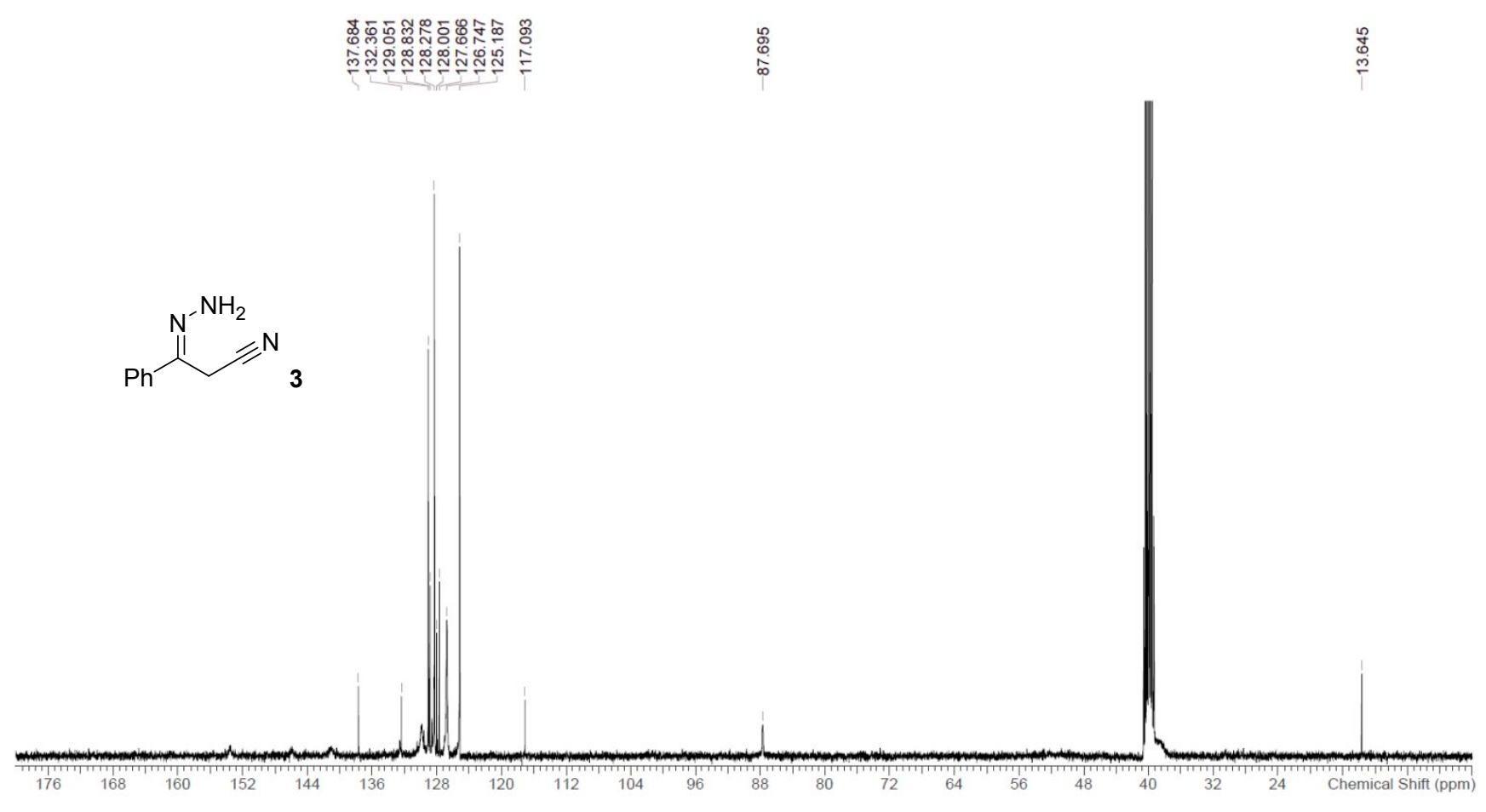

